\title{
Research on the Design of Exemplary Ecological and Environmental-friendly Architecture
}

\author{
Yanwen Wang, Xuen Hou \\ Art and Design Institute, \\ Environmental Management College of China, \\ Qinhuangdao, 066004, China
}

\begin{abstract}
Based on the background of landscape research, taking the form of landscape environment as the breakthrough point, this paper puts forward the design model of ecological and environment-friendly building in mountain region. First of all, from the aspects of spatial characteristics and structure, the mountain landscape pattern is analyzed. Secondly, the design idea of the fusion of architectural space and mountain landscape is proposed. Finally, taking the construction on mountain zushan of Qinhuangdao city as an example, the design and build exemplary ecological and environmental-friendly architecture is described in detail.
\end{abstract}

Keywords-exemplary, environmental protection, architectural design

\section{INTRODUCTION}

Mountain architecture landscape is a profound historical background, and architectural design tendency very potential. Design and development of mountain architecture landscape architecture always condensed the designers love nature, into the natural affection, the growing importance of natural landscape environment today shows strong vitality and broad design development of people[1].

Mountain architecture landscape performance for the construction and composition of other entities and elements of mountain landscape fusion form, architectural form is the blending and mountain, landscape. In the process of integration, the substrate to form a binary artificial and natural interaction, architecture and mountain landscape coordination, interaction, the continuity of the landscape space reconstruction in the mountains.

\section{ANALYSIS OF ARCHITECTURE TERRAIN AND MATERIALS}

\section{A. The selected project base}

Zushan mountain, located in Qinhuangdao city north, belong to an autonomous county, due to the north of sea, east of Yanshan peaks are made by her branch dial into the mountains, so the ancestral name, known as the Jingdong first hotel. Project base location flat terrain, left zushan East Gate, surrounded by mountains, smooth traffic, the convenient water etc.
Clever use of natural mountain environment, the integration of regional characteristics, the introduction of modern agricultural science and technology, the improvement of traditional agricultural planting and breeding, comprehensive architecture of mountain ecological culture of agricultural leisure sightseeing platform Environment-friendly of ecological architecture[2]. At the same time, through cultural landscapes and reflect the regional cultural and artistic atmosphere, attracted many artists and visitors to choose the ancestral Mountain Artist tribe as a tourist destination.

\section{B. Building material analysis}

Culture is the soul of modern tourism, the original ecological culture is an important tourism resource, progenitor estate gravel used in construction, wood, stone, glass and other ecological environment material, dear, architecture foundation and wall materials for the local gravel, concrete, formwork tamp. The four main beams for the fast-growing Chinese fir, first floor is the local stone, the two layer of the floor and roof choice of pine, between the two layers of the roof with bamboo leaves, hull, reed and so do the heat insulation and interior decoration material.

At the same time, based on the control of artificial development, design using original materials is natural layout. Fully reflects the respect for the ecological environment of the whole ecological cultural park project and fully environment-friendly design, these areas of production provides possibility to ecological architecture, sustainable.

\section{Analysis of the impact of Building mountainous terrain interaction}

The interaction effect of mountainous terrain and architecture based on ontology, especially to meet the sunshine, ventilation, density, orientation, spacing and other requirements, at the same time to get adequate sunlight and good ventilation or wind conditions, and can effectively prevent the noise pollution, so that the living environment is convenient, safe, quiet, is conducive to the user contact the communication and management. Mountainous residential planning to affinity environment, to maximize the retention of the original ecosystem, let the architecture and the nature harmonious fusion.

In the area of the outer all blend into one harmonious whole. Design planning, the mountain residential green 
architecture environment become friendly. Through the analysis of the topography, land mass, design scheme of mountainous architecture follow the unity of heaven and man thinking, such as architecture along the contour with the layout, form freely, or combination of plane and body layout; or the construction of different types of architectures and terrain elevation and area to platform based on different slope, so that each architecture the topography, and slope, returned to Taiwan staggered, so that enriched functional architectural unit, to avoid damage to the natural landscape of the mountain. Enhance the architectural design innovation concept. Not only to meet the functional living unit diversification. Building an exemplary design is not only a living space, but also the development of space, space to enjoy. And lead and the elasticity of the indoor space design, layout, segregation, segmentation flexible adjustment of planning and design.

Design of architecture is in fact to build a mode of life and space architecture. Each step all provisions of the user behavior. So, in the mountain residential design, more should be user cantered starting, let every detail of the architecture reflects the care for people. Use of terrain, physiognomy conditions of Mountainous Residential special, create expand people the feeling of space; increase the people's emotional experience of space. Let the user create a substantial living space and psychology, visual clearly in physical and mental pleasure in feeling.

\section{ANALYSIS OF MOUNTAIN ARCHITECTURE}

\section{A. Positioning function design of architectures}

In the architectural design and landscape environment platform friendly, construction and development of cultural and creative products, film and television works of art and cultural works of art creation and exhibition platform, with the natural landscape advantage to introduce domestic and foreign well-known artists established artists' studio. Collection of leisure, residential, agricultural economy demonstration, communication, art and design works show is equal to one.

\section{B. Analysis and design theory of architectural form}

Project using the ECOTEC software, to generate interactive track of sun and instant shielding analysis, any surface or any little daylight, artificial illumination, the main objective analysis of the current situation of architectural apace mountain in the planning and design is the analysis of the special base environment of mountain this geological, terrain, climate, hydrology, vegetation and other factors, thus obtains the land use suitability analysis conclusion[3]. For example: through the analysis of slope can be clearly mountainous terrain steep degree, judged by the possibility of different sections, the degree of impact on engineering economy, or through the slope to the analysis of a region of the sunshine and wind load on the merits of the specific situation and so on.

For the architectures, scientifically vertical design and create not only make full use of the terrain environment and architectural design with regional context features, should be the focus of design concept. Vertical design is particularly important in the mountainous architectures layout. Vertical design task is to use the natural terrain with architecture, choose the design elevation of scientific, consistent with the use of functional requirements, and achieve the earthwork volume, less investment, high construction speed, the comprehensive benefit of good results, as far as possible to reduce the ancestral mountain of destruction of the natural environment, the design elevation, which will determine the outside the architecture site and road of mutual coordination, determine the ground drainage way and the corresponding drainage architecture location, determine the earthwork balance scheme.

\section{The interaction of mountain and architecture}

Matching architecture and each functional based on the mountain, to form and form harmonious architectural style. Do not destroy the mountain architecture physical forms can be divided into the type that focus on the mountain the original environment, fusion and emphasizes architecture and mountains; room inside and outside environment of mutual integration, interior space partition using open planning pattern, pay attention to the mountain residential indoor door and window size, location, breaking the boundaries of traditional indoor and outdoor, wall using large landing doors and windows to expand the visual space, outdoor landscape, flowers and trees, the air into the room, the people close to natural, zero distance contact with nature[4].

Light from the sun to the indoor through the door, window transmission, not only can increase the indoor lighting, more important is the light from the sun can remove mildew, kill bacteria, the protection of the indoor environment and indoor air fresh, also can alleviate the tired people. Conformal is architecture and combined shape enclosed mountain, mountain environment landscape; beyond the type that emphasizes the orderly combination of architectural function zoning and mountain. Mountain architecture design to suit one's measures to local conditions, combined with the terrain, do section, energy conservation, resource conservation, and construction, landscape and city environment organically together. These design methods have been widely reflected in the traditional and modern mountain architecture. 


\section{DESIGN OF ECOLOGICAL AND ENVIRONMENTAL- FRIENDLY MOUNTAIN ARCHITECTURE}

A. Design scheme

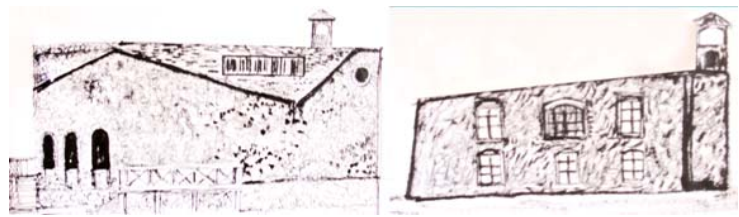

Figure 1: The architectural design sketch

The use of ECOTECT software, to generate a variety of analysis diagram and related data, the mountainous terrain environment is complex, involving many factors such as natural environment, need to be efficient, accurate, clear image, analysis of data, generating model information analysis chart produced by design sketches and later CAD topographic map and GIS software. The above situation, with architectural design schematic is shown in Figure 1.

\section{B. The actual architecture}

The surface shape base forms, one is the embodiment of the base shape of the architectural form is the pursuit of architectural and topographical blend, architecture plane to try to fit with the base shape, not by blunt geometry shape to occupy the free change of the mountain architecture plane, profile consistent with the base situation, take the morphological structure of drop.

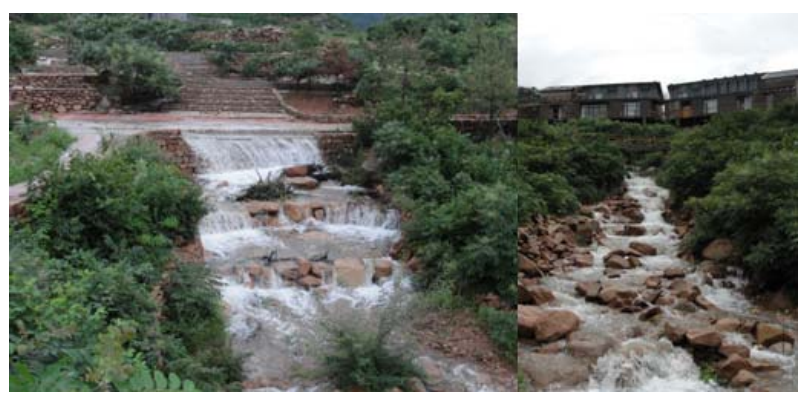

Figure 2: Blended scene of architectural landscape and water in summer

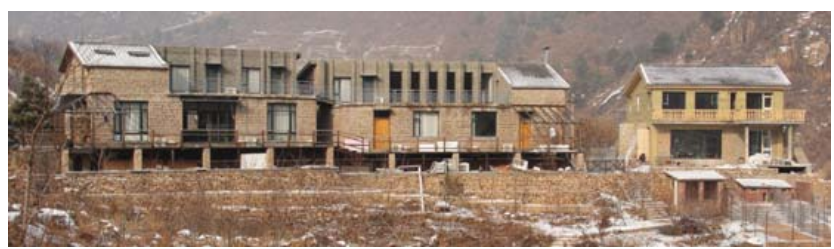

Figure 3: Blended scene graph of architectures and mountain in winter

To maintain the original natural river shoreline, natural alignment and cross section and vegetation, therefore, the performance of base shape of the mountain architecture form is very ecological rationality, it is close to the mountain terrain, the environment changes very little. Figure 2 shows the context graph construction and water environment in summer and blend with each other. Figure 3 shows the architecture in the winter and mountain mutual fusion scene graph.

Conclusion

Taking the landscape environment of morphological structure as a starting point, this work studies the architectural form design as a target. According to the design of the related research results, the landscape shape analysis carried out from the landscape entities and spatial characteristics of landscape, landscape structure. The design strategies of architectural form, from the fusion between adaptation to invisible structural order and strengthening, and entity element association, the external form of the building space and landscape space to discuss. Using the zushan mountain natural resources creates a greater influence of building demonstration zone.

\section{ACKNOWLEDGEMENTS}

The research work was supported by the Key Projects in 2013 Hebei Province Science \& Technology Pillar Program under Grant No. 13236010.

\section{REFERENCES}

[1] Zhang, Z. The development practice of mountainous architecture. Architectural Design Management, 31(05), pp.57-58, 2014.

[2] Luo, N. Evaluation and analysis on the external effects of mountain building design pattern based on CFD. Jiangxi Building Materials, 34(19), pp. 28-29, 2014.

[3] Lin, B. H. Discussion on some mountain building structure design. Doors and Windows, 8(07), pp.237-238, 2014.

[4] Zhang, D. Y. Analysis of energy saving and environmental protection building design. Technology Guide, 21(06), pp.324-325, 2013. 